\title{
Laparoscopic-Assisted Pull-Through for Congenital Rectal Stenosis
}

\author{
Martin L. van Niekerk, MD, Andre Visser, MD, and Daniel J. Venter, MD
}

\begin{abstract}
Congenital rectal stenosis is a rare condition. In this article, we report on a 30-day-old infant with rectal stenosis who underwent a successful laparoscopic pull-through operation. The laparoscopic method allows the surgeon to mobilize the rectum within the muscle complex without the division of any muscles of continence.
\end{abstract}

\section{Introduction}

A NORECTAL MALFORMATIONS include a wide spectrum of anomalies and occur in about 1 in 4000-5000 live births. ${ }^{1}$ Rectal stenosis is one of the most rare types of anorectal malformations. In this anomaly, the stenotic rectum lies within the levator animuscle complex, the patient has a normal anal canal, and there is usually no fistula. ${ }^{2}$ In 2000, Keith Georgeson proposed a laparoscopic approach as part of a new technique to repair high imperforate anal defects. ${ }^{3}$ This technique allows excellent visualization and definition of the pelvic anatomy without the saggital division of muscles. In this article, we present what we believe to be the first case report of a laparoscopic-assisted pull-through procedure for a congenital rectal stenosis.

\section{Patient and Method}

A 2-week-old, 3.1-kg male baby was admitted 14 days after birth, with symptoms of bowel obstruction and abdominal distension. There was a history of frequent passing of small liquid stools. On perineal inspection, the baby had a normal anus, but the rectal examination revealed a blind-ending anal canal (Fig. 1).

\section{Method}

The baby was resuscitated, and an emergency sigmoid colostomy was carried out. A subsequent cologram, using water-soluble contrast, showed a distended distal sigmoid colon with a rectal stenosis (Fig. 2).

\section{Surgical technique}

The patient was operated on 14 days after the colostomy procedure, using a laparoscopic and transanal approach. He was placed in a supine position transversely across the end of the table. The bladder was catheterized to prevent postoperative urinary retention and also to allow palpation of the urethra during the dissection. A 5-mm camera port was placed just above the umbilicus, and a pneumoperitoneum was established. One 3-mm port each was placed in the upper and lower left quadrants of the abdomen. Another 5-mm port was placed in the lower right quadrant. The dissection was started at the level of peritoneal reflection. The whole rectum with the distal stenotic part was mobilized by using monopolar hook coagulation (Fig. 3). The rectum was mobilized as far as its connection with the blind-ending anal canal. A Lone Star retractor (Lone Star Medical Products, Houston, TX) was used to keep the anal canal open (Fig. 4). A circumferential incision was made in the proximal part of the blind-ending anal canal. The rectum was grasped and extracted through the anus. The stenotic rectum was then resected, and rectoanal anastomosis was accomplished with interrupted 5.0 Vicryl sutures (Johnson \& Johnson, Johannesburg, South Africa) (Fig. 5).

The total operating time was 88 minutes. The postoperative course was uneventful. The patient was discharged on the postoperative day 3. A single anal dilatation was done after the laparoscopic operation, and the colostomy was closed 2 weeks later. The patient is now 2 months postcolostomy closure and passes an average of three normal stools a day.

\section{Discussion}

Rectal atresia and stenosis are rare types of anorectal malformations. They comprise no more than $1-2 \%$ of the entire spectrum of anorectal malformations. ${ }^{4}$ The exact pathogenesis of rectal stenosis is not known, but it might be a secondary development from an intrauterine vascular accident involving the middle and superior rectal arteries. Genetic and environmental factors may also be responsible. ${ }^{5}$ In the main Wingspread classification, rectal stenosis has been tabulated as a rare malformation ${ }^{6}$ and in the International Krickenbeck Classification as a rare variant of the major clinical groups. ${ }^{7}$

Department of Pediatric Surgery, University of Pretoria, Pretoria, South Africa. 


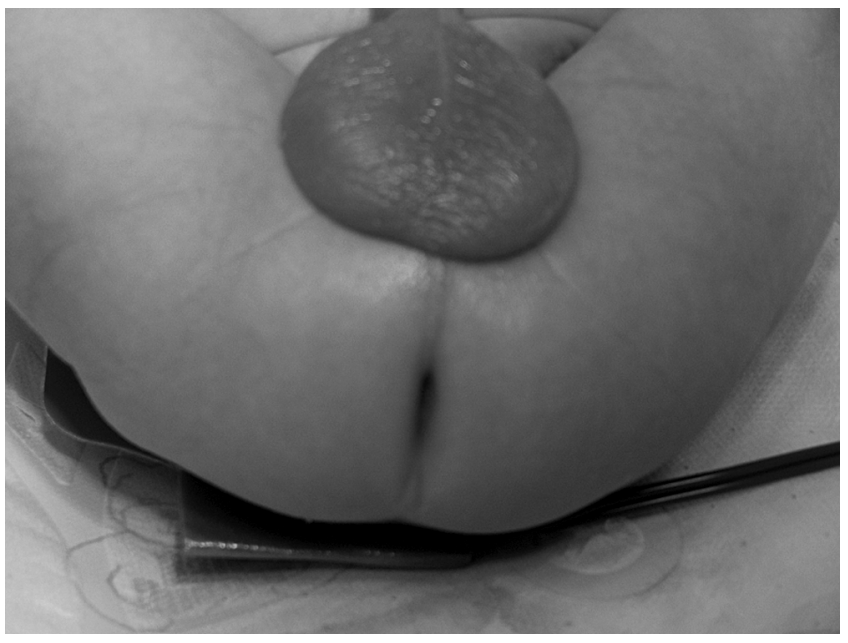

FIG. 1. On perineal inspection, the anus appeared normal.

Patients with this anorectal anomaly have a well-developed anus. The internal and external sphincters are normal, but are occasionally incompletely developed. The stenotic rectum lies within a normally developed levator animuscle complex. There are usually no fistulous communications of the urinary tract or vagina. ${ }^{4}$

Many innovative techniques have been used in the past to treat rectal stenosis, ${ }^{8}$ including posterior saggital anorectoplasty (PSARP). ${ }^{9}$ Since the introduction of the laparoscopicassisted anorectal pull-through operation in 2000, this method has been a safe, useful treatment for anorectal malformations. ${ }^{10}$ It accomplishes the same anatomic end result as the PSARP technique while minimizing the risk of injury to the surrounding anatomic structures. Liem and Hien ${ }^{10}$ published a

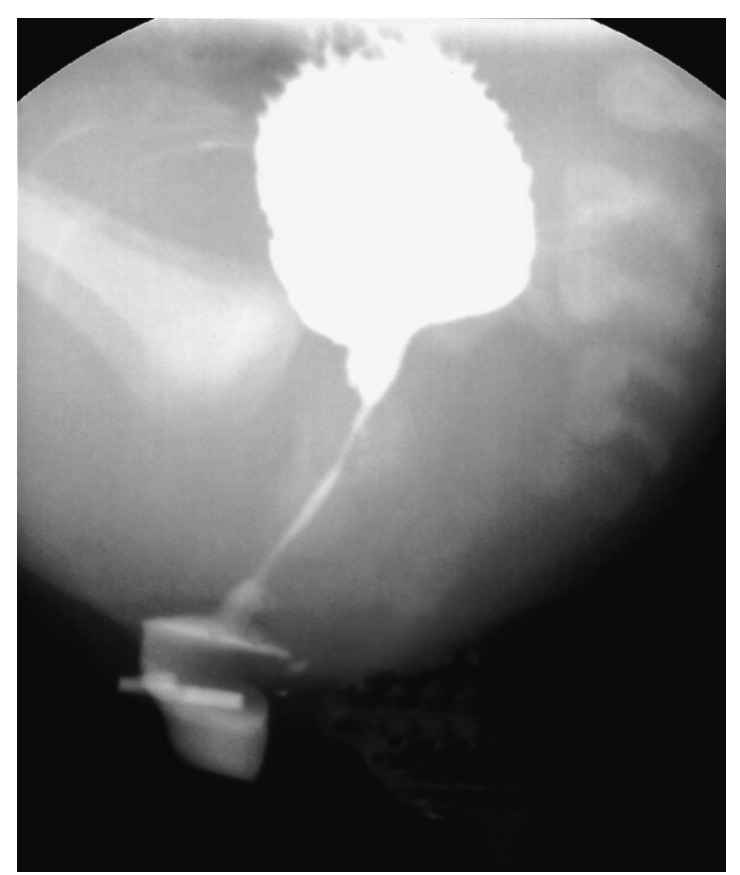

FIG. 2. Cologram through sigmoid colostomy showing rectal stenosis.

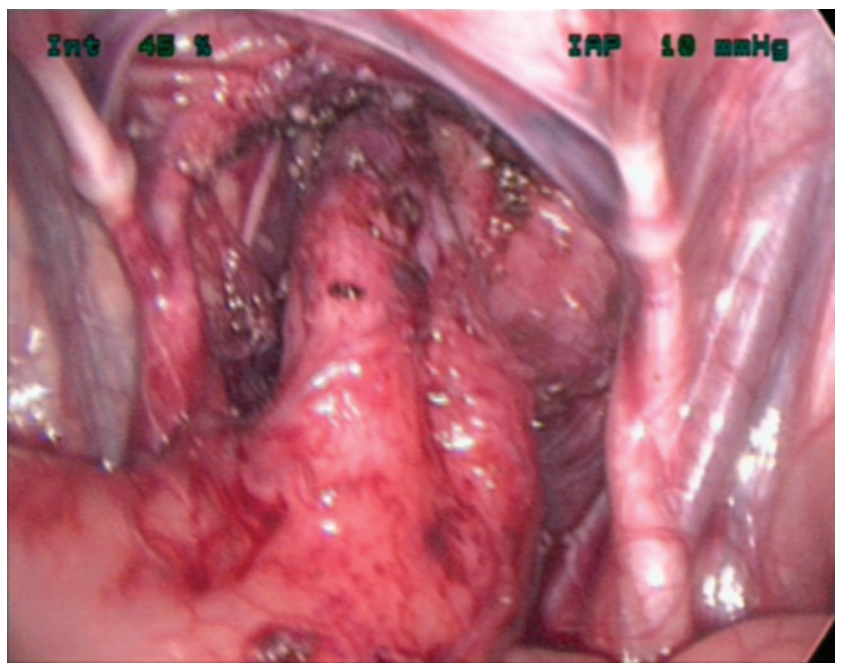

FIG. 3. Laparoscopic view of the mobilized rectum.

report on the laparoscopic and transanal approach for rectal atresia in 2 patients. In our report, we show that rectal stenosis can also be treated successfully by the laparoscopic approach.

In our patient, the laparoscopic-assisted method allowed excellent pelvic vision of the levator muscle complex and enabled us to mobilize the rectum within the muscle complex. By staying close to the rectal wall during dissection, we minimized the chance of any injury to surrounding anatomic structures and the muscles of continence. Laparoscopic mobilization was very easy because of the absence of fistulas in this patient. Additional advantages of the laparoscopic method include less pain and potentially fewer perineal wound complications.

\section{Conclusion}

The laparoscopic-assisted repair of rectal stenosis is an ideal method with which to treat this rare anorectal malformation. It allows proper placement of the pull-through rectum in the levator muscle complex, without dividing any muscle of continence. These patients usually have a normal anal canal and

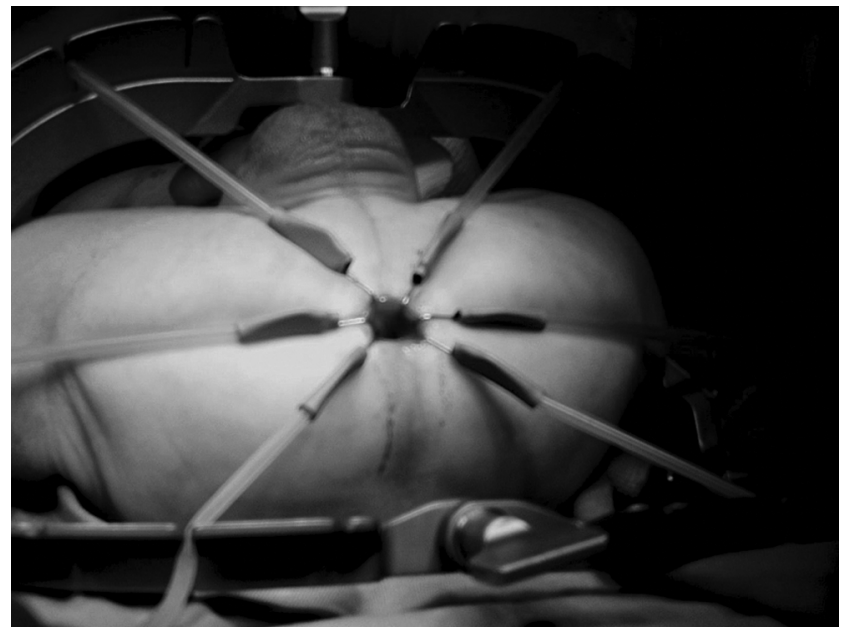

FIG. 4. Coloanal anastomosis done with the aid of the Lone Star retractor (Lone Star Medical Products, Houston, TX). 


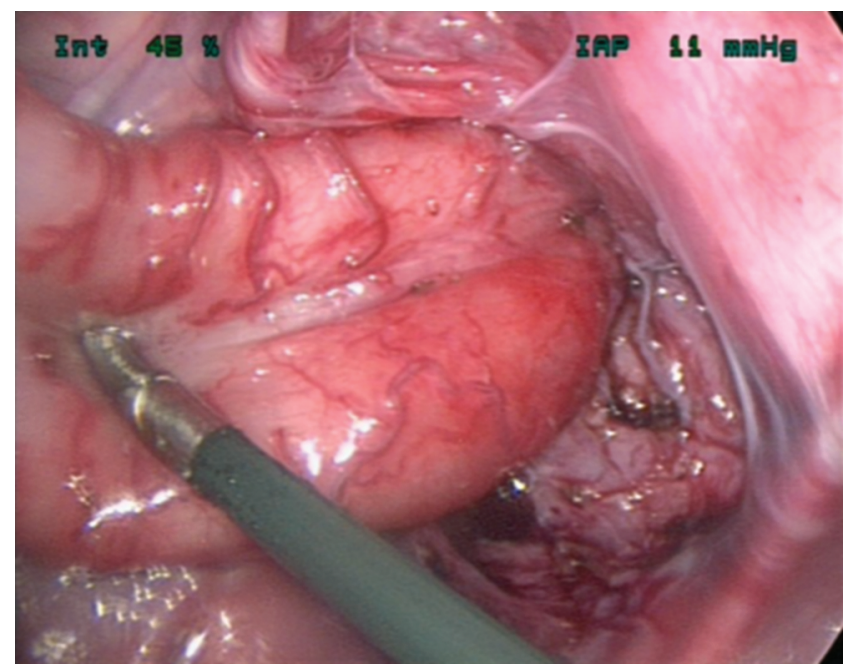

FIG. 5. Pelvic view of colon after completion of the pullthrough.

internal and external sphincter, and should have a good prognosis for continence.

\section{Disclosure Statement}

No competing financial interests exist.

\section{References}

1. Sydorak RM, Albanese CT. Laparoscopic repair of high imperforate anus. Sem Pediatr Surg 2002;11:217-220.

2. Zia-ul-Miraj AM, Brereton RJ, Huskisson L. Rectal atresia and stenosis. J Pediatr Surg 1995;30:1546-1550.
3. Georgeson KE, Inge TH, Albanese CT. Laparoscopically assisted anorectal pull-through for high imperforate anus--a new technique. J Pediatr Surg 2000;35:927-931.

4. Gangopadhyay AN, Sinha CK, Sahoo SP. Combined rectal atresia and rectal stenosis. Pediatr Surg Int 1997;12:605-606.

5. Dorairajam T. Anorectal atresia. In: Stephen FD, Smith ED, Paul NW (eds): Anorectal Malformations in Children: Update 1988. New York: Liss, 1988, pp. 105-110.

6. Smith ED. Classification of anorectal anomalies. In Stephen FD, Smith ED, Paul NW (eds): Anorectal Malformations in Children: Update 1988. New York: Liss, 1988, pp. 105-110.

7. Holschneider A, Hudson J, Pena A. Preliminary report of the international conference on the development of standards for the treatment of anorectal malformation. J Pediatr Surg 2005;40:1521-1526.

8. Upadhyaya P. Rectal atresia: Transanal, end-to end, rectorectal anastomosis: A simplified, rational approach to management. J Pediat Surg 1990;25:535-537.

9. Pofia A, Hong A. Advances in the management of anorectal malformations. Am J Surg 2000;180:370-376.

10. Liem NT, Hien PD. Laparoscopic and transanal approach for rectal atresia: A novel alternative. J Pediatr Surg 2007;42: E25-E27.

Address correspondence to: Martin L. van Niekerk, MD Department of Pediatric Surgery University of Pretoria 204 Kloof MediClinic 511 Jochemus Street 0048 Pretoria South Africa

E-mail: mlvanniekerk@axxess.co.za 

Copyright of Journal of Laparoendoscopic \& Advanced Surgical Techniques is the property of Mary Ann Liebert, Inc. and its content may not be copied or emailed to multiple sites or posted to a listserv without the copyright holder's express written permission. However, users may print, download, or email articles for individual use. 